\title{
Comparison between Cement and Concrete Waste on the Strength Behaviour of Marine Clay Treated with Coal Ash
}

\author{
Nadiah Jamaludin ${ }^{1, *}$, Nor Zurairahetty Mohd Yunus ${ }^{1}$, Ahmed Mohammed Awad \\ Mohammed ${ }^{1}$, Zuriana Haron ${ }^{1}$, Aminaton Marto ${ }^{2}$, Nordiana Mashros ${ }^{1}$, Norhidayah Abdul \\ Hassan $^{1}$ and Mariana Aida Abdul Kadir ${ }^{1}$ \\ ${ }^{1}$ Faculty of Civil Engineering, Universiti Teknologi Malaysia, 81310 UTM Skudai, Johor, Malaysia \\ ${ }^{2}$ Department of Environmental Engineering \& Green Technology, Malaysia-Japan International \\ Institute of Technology, Universiti Teknologi Malaysia Kuala Lumpur, 54100 Kuala Lumpur, \\ Malaysia.
}

\begin{abstract}
This paper aims to compare the strength behaviour of demolished concrete material (DCM) and ordinary Portland cement (OPC) in addition to coal ash for stabilizing marine clay, thus determining the optimum mix. Coal ash with different ratio of bottom ash (BA) and fly ash (FA) were prepared at various percentages (i.e. 3\%, 6\% and 8\%). In addition, limited amount of DCM and OPC of $2 \%$ was added at different curing periods of 0,7 and 28 days respectively. Thus, the percentage of admixture added to the marine clay were $5 \%, 8 \%$ and $10 \%$ respectively. Unconfined compressive strength (UCS) test was done and the results revealed that the strength of treated marine clay soil increased significantly with increment percentage of coal ash and also for both DCM and OPC. For admixture with OPC, treated marine clay with 5\% admixture shows the highest strength gained, while the effective combination between bottom ash and fly ash is 50:50. At the first 7 days the strength gain was very high but from 7 days to 28 days the gain of strength was reduced. While for DCM, 5\% of additive at 30BA:70FA shows the highest strength. In addition, both OPC and DCM provide significant strength gained between 0-7 days and decrease for 7-28 days. In conclusion, when comparing both stabilizer, OPC is a much more efficient secondary stabilizer when reacted with coal ash. As it provide early gain in strength with a much higher strength.
\end{abstract}

\section{Introduction}

Globally, generation of coal ash waste is increasing at alarming rate. It is predicted in International Energy Outlook 2009 that a projection of $88 \%$ increase is expected in coal combustion for countries such as United States, China and India between the year 2006 and 2030 [1]. Moreover, the coal ash waste continues to increase to a rate of 131 million tons per year in United States[1]. In India, 120 of the coal power plants contributes $70 \%$ of

* Corresponding author: nadiahjamaludin7@gmail.com 
electricity which in return produces 120-150 million tons of fly ash per year [2],[3]. Despite generating a high volume of fly ash waste, the rate of utilization in the construction field is only $38 \%$ [2].

In Malaysia, there are five coal fired electric power station which are Tanjung Bin (Johor), Kapar (Selangor), Jimah (Negeri Sembilan), Manjung (Perak), and lastly Sejingkat (Sarawak) [4]. When burning coal, 80-90\% of unburned coal constitutes of Fly ash while the remaining 10-20\% are bottom ash [5]. Coal ash waste generated by Tanjung Bin power station itself produce 180 tonnes of bottom ash and 1620 tonnes of fly ash daily [6]. This shows that there is an abundance of coal ash waste waiting to be utilized. Moreover, due to the high costs in constructing coal ash ponds as a mean of dumping site, power plants' authorities are finding new ways in order to explore the feasibility of beneficial uses of existing coal ash to cater for disposal of newly generated coal ash.

Out of the 76 percent of solid waste that are collected in Malaysia, only 5\% is recycled with $95 \%$ of waste dumped at landfills [7]. From the statistics provided above, it shows that there is an alarming need to used coal ash waste which in this case is stabilizing marine clay soil. By using coal ash waste in soil stabilization it could help reduce environmental pollution due to the abundance of waste in landfills and also lessen the cost of creating ponds for disposal of these waste.

Marine clay could be found abundantly around the coastal and offshore areas and also beneath the ocean bed [8]. It is considered as a problematic soil due to its low strength and also high compressibility properties. Marine clay could easily susceptible to swelling and shrinking due to changes in moisture content [9]. Thus, this type of soil is considered unsuitable for any construction or development is done on it. Visually, it could be observed that the colour of marine clay soil ranges from black to dark grey to dark brown. The grey colour of the marine clay is attributable to the oxidation of sulphur and iron from the clay due to it being exposed in the atmosphere.

Hence, this paper aims to compare the strength characteristics of marine clay stabilized with coal ash and Ordinary Portland cement(OPC) or demolished concrete material (DCM). Moreover, the outcome of this paper would determine whether coal ash waste would be able to reutilize together with both OPC and DCM.

\section{Materials}

Materials used for this particular research were marine clay, coal ash which consists of fly ash and bottom ash, Ordinary Portland cement (OPC) and demolished concrete material (DCM). Coal ash was used as the main stabilizer while OPC or DCM were used as a secondary stabilizer.

Marine clay for this study was obtained from Nusajaya which is a developing housing site in Johor Bahru. Coal ash consists of a combination of fly ash and bottom ash produced from an industrial-by waste product that could found abundantly at offshore construction or plant generation site [10]-[12]. For this particular research, coal ash from Tanjung Bin Power Plant was used. Both OPC and DCM were obtained from the Structural Lab at Universiti Teknologi Malaysia.

\subsection{Sample Preparation}

The testing and material preparation was done according to BS 1377:1990. For this particular research unconfined compressive strength test (UCS) was done in order to determine the compressive strength of soil which is suitable to be done on clay soil. A cylindrical specimen of $38 \mathrm{~mm}$ in diameter and $76 \mathrm{~mm}$ in height was formed for this particular test. The maximum value of compressive force is the unconfined compressive 
strength of the soil. However, in order to prepare the sample before UCS testing being carried out, the Maximum Dry Density (MDD) and Optimum Moisture Content (OMC) from standard proctor compaction test are required to determine the calculated amount of the raw materials mixture.

There is no proper preparation for fly ash as it can be used directly as it is readily dry compared to bottom ash. The same goes for OPC. Due to the condition of this study that requires fine materials to be used, the bottom ash needs to be sieved for passing $2 \mathrm{~mm}$ sieve as the bottom ash is coarser than fly ash. Lastly, the DCM materials were ground into fine materials and pulverized to obtain a powder form and sieved passing $63 \mu \mathrm{m}$. In terms of soil mixtures, the combination of stabilizers amounts to 5,8 and $10 \%$. This is inclusive of the $2 \%$ of secondary stabilizers which are DCM and OPC and 3, 6 and $8 \%$ of coal ash waste. The coal ash waste was mixed at a ratio of 70BA:30FA, 50BA:50FA and 30BA:70FA.

\section{Results and Discussion}

The results gained from laboratory testing are summarized and discussed here. The results from unconfined compressive strength (UCS) test are discussed over the strength of treated marine clay according to the percentage of additive, curing period and various proportion of coal ash other than compared with UCS untreated samples for both OPC and DCM stabilizer. Table 2 shows a comparison of compressive strength for both OPC and DCM stabilizer mix with coal ash to stabilize marine clay.

Table 2. Comparison of compressive strength for both OPC and DCM stabilizer mix with coal ash to stabilize marine clay

\begin{tabular}{|c|c|c|c|c|c|}
\hline \multirow{2}{*}{$\begin{array}{l}\text { Secondary } \\
\text { Stabilizer }\end{array}$} & \multirow{2}{*}{$\begin{array}{c}\text { Additive } \\
\text { percentages } \\
(\%)\end{array}$} & \multirow{2}{*}{$\begin{array}{l}\text { Ratio of } \\
\text { BA: FA }\end{array}$} & \multicolumn{3}{|c|}{ Curing Period (Days) } \\
\hline & & & 0 & 7 & 28 \\
\hline \multirow{10}{*}{$\begin{array}{c}\text { Demolished } \\
\text { Concrete } \\
\text { Material }\end{array}$} & 0 & - & \multicolumn{3}{|c|}{88.1} \\
\hline & & $70: 30$ & 229.02 & 251.82 & 208.34 \\
\hline & & $50: 50$ & 119.44 & 226.03 & 238.21 \\
\hline & 5 & $30: 70$ & 220.47 & 317.73 & 344.13 \\
\hline & \multirow[b]{3}{*}{8} & $70: 30$ & 124.99 & 166.17 & 190.99 \\
\hline & & $50: 50$ & 123.58 & 183.58 & 197.38 \\
\hline & & $30: 70$ & 155.72 & 280.18 & 311.04 \\
\hline & \multirow[b]{3}{*}{10} & $70: 30$ & 119.35 & 145.76 & 178.37 \\
\hline & & $50: 50$ & 127.05 & 177.95 & 176.59 \\
\hline & & $30: 70$ & 180.06 & 212.23 & 240.63 \\
\hline \multirow{9}{*}{$\begin{array}{c}\text { Ordinary } \\
\text { Portland } \\
\text { Cement }\end{array}$} & \multirow[b]{3}{*}{5} & $70: 30$ & 308.1 & 357 & 378.3 \\
\hline & & $50: 50$ & 405 & 449.4 & 507.7 \\
\hline & & $30: 70$ & 281 & 440.4 & 458.4 \\
\hline & \multirow[b]{3}{*}{8} & $70: 30$ & 208.3 & 332.1 & 341.5 \\
\hline & & $50: 50$ & 263.3 & 430.7 & 437.5 \\
\hline & & $30: 70$ & 187.2 & 355.6 & 357.3 \\
\hline & \multirow[b]{3}{*}{10} & $70: 30$ & 140.1 & 282 & 316.7 \\
\hline & & $50: 50$ & 178.7 & 366.6 & 350.7 \\
\hline & & $30: 70$ & 162.4 & 358.5 & 347.6 \\
\hline
\end{tabular}


Figure 1 shows the comparison of compressive strength based on curing periods between OPC and DCM for different percentages of additives. From the graphs it could be perceived that the strength for all treated marine clay is higher than untreated marine clay. For 5\% additives, the highest strength obtained is for OPC at a ratio of 50BA:50FA at 28 days which is $507.7 \mathrm{kPa}$. This shows an increase in strength of $471 \%$ when compared with the untreated marine clay. With the presence of cement, the strength of soil sample would increase due to the drying of soil and cement mix which is called hydration and also the presence of cementitious product [13]. While the lowest strength is for DCM of 50BA:50FA at 0 day which is $119.44 \mathrm{kPa}$. This shows an increase in strength of $35.6 \%$ as compare to untreated soil. However, the sample of 5\% additive of DCM mixed with less fly ash proportions are the only samples that decreased in strength. This may be caused by the reduced reactions of pozzolanic activity from 7 day to 28 day thus causing the strength to be decreased. Furthermore, for $8 \%$ additives the highest strength could be observed from the graph is also OPC at a ratio of 50BA:50FA at 28 days which is $437.5 \mathrm{kPa}$. The increase in strength is $396.6 \%$ which is lower than $5 \%$ additives. Other than that, the lowest strength of treated sample for $8 \%$ additives is DCM at ratio 50BA:50FA at 0 days which is $123.58 \mathrm{kPa}$ which shows an increment of strength of $40 \%$. With the addition of $10 \%$ additives, the highest strength that could be identified from the graph is OPC with the ratio of also 50BA:50FA which is $366.6 \mathrm{kPa}$. The strength increase is $316 \%$ which is lower than both $5 \%$ and $8 \%$. The reason for this phenomenon could be due to the higher quantity of fly ash and bottom ash for $8 \%$ and $10 \%$ as compared to $5 \%$. Hence, there is not enough $\mathrm{Ca}^{2+}$ to react this coal ash together with OPC. The lowest strength from the addition of $10 \%$ additives is DCM at 70BA:30FA which is $140.1 \mathrm{kPa}$. Increment of strength for this particular value is $59.7 \%$ which is higher than both $5 \%$ and $8 \%$. Hence the highest strength obtained if for OPC at a ratio of 50BA:50FA for all percentages of additives. The optimum percentage is $5 \%$ for both OPC and DCM as it gave the highest strength for most samples.

From the graphs in Figure 1, it could be perceived that with increasing curing period mostly the strength of the treated marine clay specimens increased significantly as compared to the untreated samples. Besides, as seen in the graph, the increased amount of fly ash lead to increasing strength of treated samples compared bottom ash. This agree with earlier findings by [13] that stated the increased amount of finer particles which are fly ash filled up the void between larger particles will improve the interlocking between materials mixed including bottom ash, other than the hydrolysis activity takes place thus increased the strength of the samples.

Moreover, the highest strength gain could be determined at $5 \%$ of additives. From the graphs in Figure 1, it could be determined that the strength gain is highest at 0 day curing period. At 5\% additives, the highest strength gain was acquired at 0 day for OPC with a ratio of 50BA:50FA which is $359.7 \%$, while the lowest strength gain is at 7-28 days for DCM with a ratio of 70BA:30FA. For $8 \%$ additives, similar to $5 \%$ additives the strength gain is highest at OPC with a ratio of 50BA:50FA which is $198.86 \%$. This value is lower when compared to strength gain at 5\%. Furthermore, the lowest strength gain for $8 \%$ is at $7-28$ days for OPC at a ratio of 30BA:70FA which is $0.48 \%$. Next, strength gain at $10 \%$ is the highest at 0-7 days for OPC at a ratio of 30BA:70FA which is $120.75 \%$ while the lowest strength gain is at 7-28 days for OPC at a ratio of 50BA:50FA. Hence it could be determined that OPC is good for early strength gain up to 7 days. Beyond that curing period, the strength would still increase but the percentage of strength gain will decrease. 


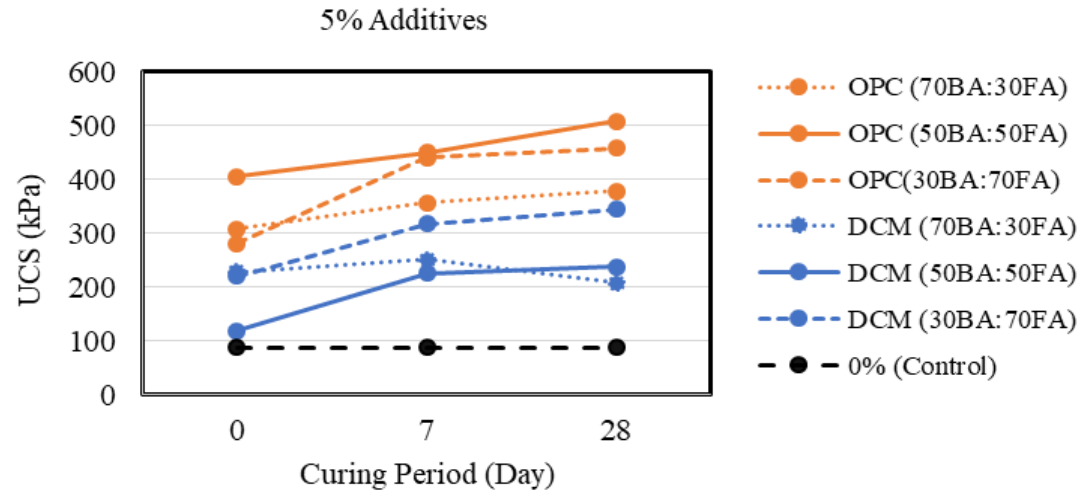

(a)
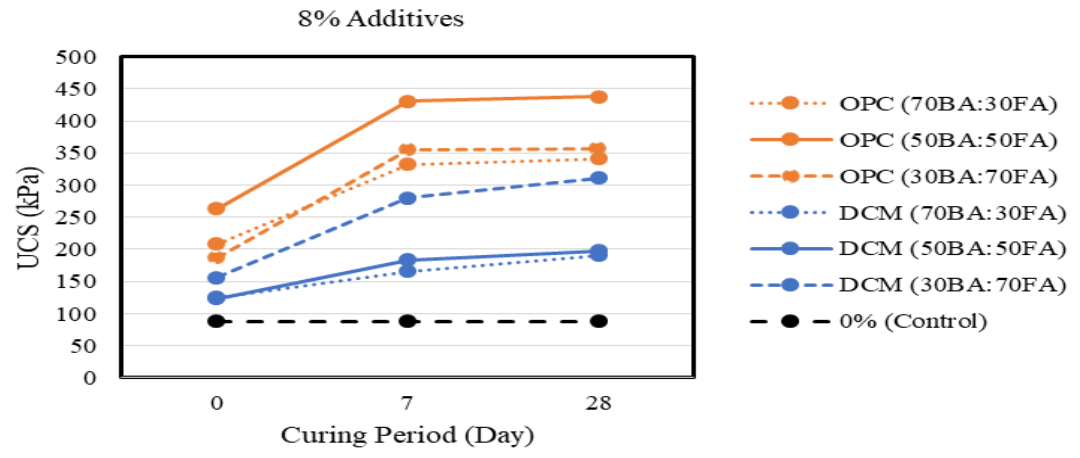

(b)
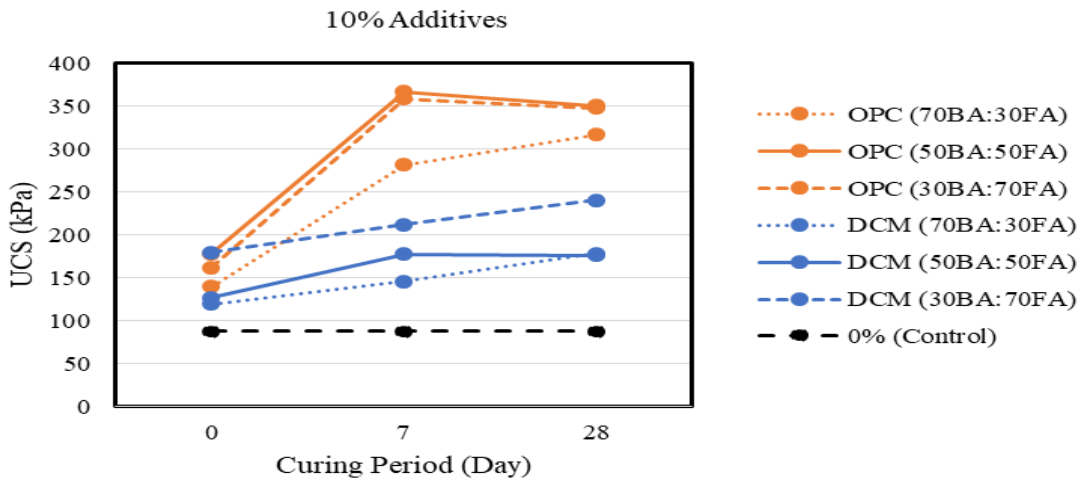

(c)

Fig. 1. Comparison of compressive strength based on curing periods for (a) $5 \%$ additive percentage (b) $8 \%$ additive percentage (c) $10 \%$ additive percentage.

Figure 2 shows a comparison of compressive strength based on percentage of additives for different curing periods which are 0,7 and 28 days. By referring to the 0 day graph, it could be deduced that the highest strength is obtained with addition of 5\% additives at a ratio of 50BA:50FA for OPC which is $405 \mathrm{kPa}$. Furthermore, the lowest strength at 0 day was also obtained at 5\% additives of DCM with a ratio of 50BA:50FA 
which is $119.44 \mathrm{kPa}$. While for 7 days curing period, the highest strength for treated marine clay attained is also at 5\% additives of OPC at ratio of 50BA:50FA which is $449.4 \mathrm{kPa}$. The strength of treated marine clay at 7 days curing period is higher when compared with 0 day at the same curing percentage of additives and ratio. This shows that with increasing curing period, the strength of treated marine clay would also increase. This is due to pozzolanic reaction as a result of soil stabilized with cement. Crystalline compound would formed and harden over time thus increasing the strength of soil mixture [14]. The lowest strength for curing period of 7 days obtain is at $10 \% \mathrm{DCM}$ at a ratio of 70BA:30FA which is 145.76 $\mathrm{kPa}$. Similar to previous curing period, the highest strength of treated marine clay was obtained at 5\% additives for OPC at a ratio of 50BA:50FA which is $507.7 \mathrm{kPa}$. At 28 days curing period, the lowest strength for treated marine clay is with the addition of $10 \%$ additives of DCM with ratio of 50BA:50FA which is $176.59 \mathrm{kPa}$. This value is higher when compared with curing periods of 0 and 7 days. The entire marine clay sample treated with OPC strength would increase with increasing curing period, while for DCM treated sample the strength were not consistent. It can be concluded that the cementitious agent in DCM are not consistent and it may effects the hydrolysis activity of the samples. This is due to the inconsistency of cement presence in the DCM sample as only a representative sample was taken. Furthermore, DCM has a lower cement content which makes the strength of sample much lower than OPC. Besides, the smaller percentage of addictive which are 5\% gives the higher strength of the samples according to the increment of curing period respectively. [15] quote that stabilizers with higher amount of cementitious agent such as cement will enhanced the pozzolanic reactions to takes place as it will support the main stabiliser such as fly ash and bottom ash, thus increasing the strength of the soil samples.

0 Day
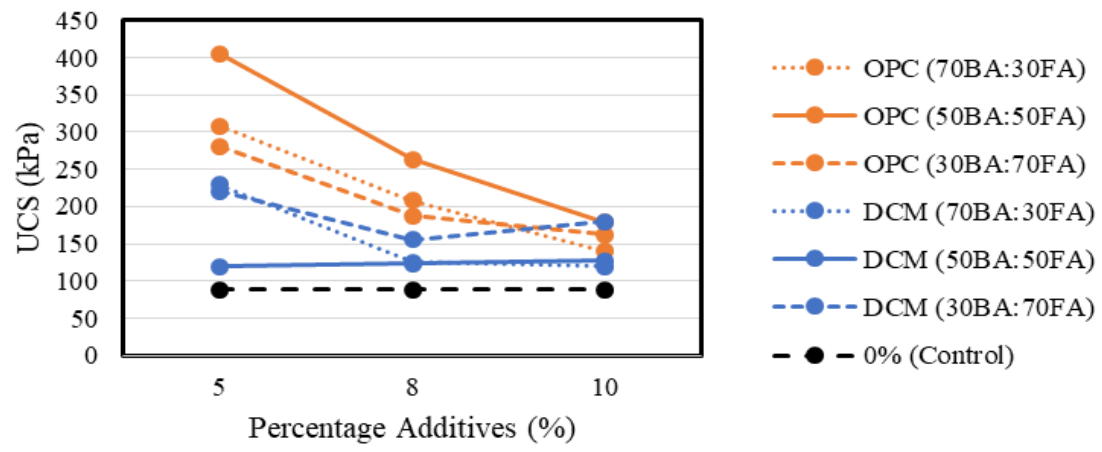

(a)

7 Days

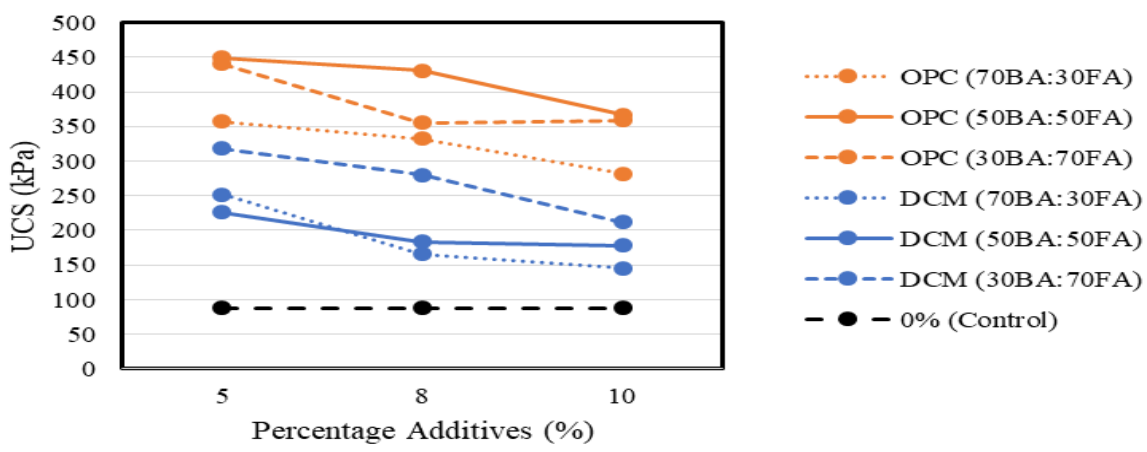


(b)

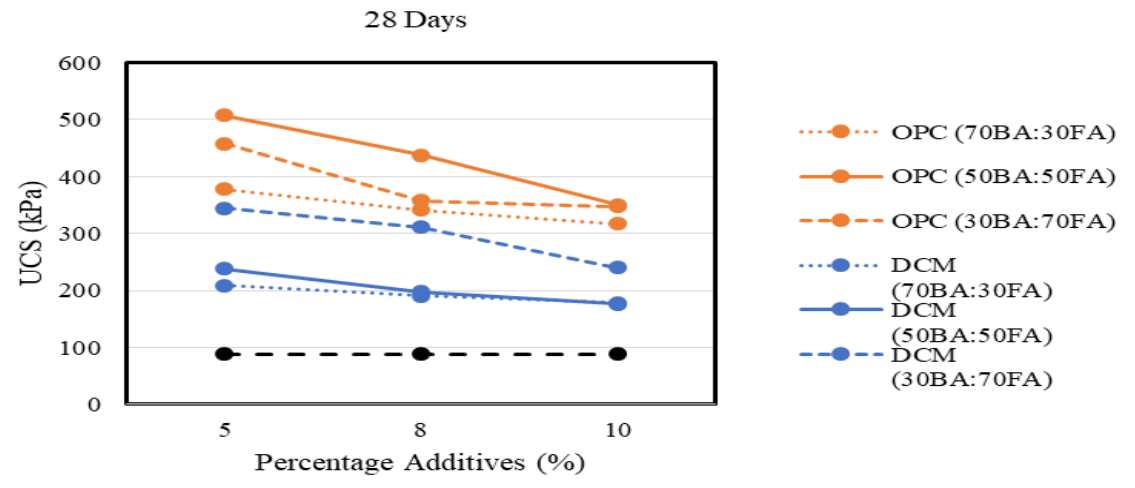

(c)

Fig. 2. Comparison of compressive strength based on percentage of additives for (a) 0 day (b) 7 days (c) 28 days curing period

\section{Conclusion}

As a conclusion, both OPC and DCM with coal ash when mixed with marine clay soil exhibits increased in strength. The strength of soil sample increased with decreasing proportion of coal ash over curing period. Addition of stabilizer at 5\% displays the highest strength when compared with other higher percentage of the stabilizer. Besides, the strength of treated samples also significantly increased with increment proportion of fly ash compared to bottom ash. It can be shown that the strength of treated soil sample with DCM at a ratio of 30BA:70FA is the highest strength it can be achieved. However, the strength of soil sample stabilized with coal ash and DCM is not consistent. This is due to the inconsistency of cement present in the DCM sample as only a representative sample was taken. Furthermore, DCM has a lower cement content which makes the strength of sample much lower than OPC. For soil sample treated with OPC, marine clay soil with 5\% of additives with a ration of 50BA:50FA has the highest strength. For both stabilizers, the first 7 days of strength gain was very high but from 7 days to 60 days the strength gain tends to decrease.

It can be concluded that the mixture of coal ash as the main stabilizer and DCM or OPC as a secondary stabilizer is effective in the stabilizing Nusajaya's marine clay as it gives very high strength at an earlier stage. The most effective mixture based on this study is $5 \%$ addition of coal ash and OPC as it provides early gain in strength with a much higher strength when compared with DCM.

\section{References}

1. D. J. Tenenbaum, "Trash or Treasure? Putting Coal Combustion Waste to Work," Environ. Health Perspect., vol. 117, pp. 490-497, (2009)

2. B. Lokeshappa and A. K. Dikshit, "Disposal and Management of Flyash," vol. 3, pp. 11-14, (2011) 
3. M. Jain, "Fly ash - waste management and overview : A Review Fly ash - waste management and overview : A Review," no. (January 2014, 2015)

4. N. Nordin, M. M. A. B. Abdullah, M. F. M. Tahir, A. V. Sandu, and K. Hussin, "Utilization of Fly Ash Waste As Construction Material.," Int. J. Conserv. Sci., vol. 7, no. 1, pp. 161-166,(2016)

5. A. U. Abubakar, K. S. Baharudin, and I. Technology, "Potential Use of Malaysian Thermal Power Plants," vol. 3, no. 2, pp. 25-37, (2012)

6. A. Muhardi, A. Marto, K. A. Kassim, A. M. Makhtar, L. F. Wei, and Y. S. Lim, "Engineering characteristics of Tanjung Bin coal ash," Electron. J. Geotech. Eng., vol. $15 \mathrm{~K}$, pp. 1117-1129, (2010)

7. E. Papargyropoulou, D. C. Preece, D. R. Padfield, and A. A. B. Abdullah, "Sustainable construction waste management in Malaysia: a constructor's perspective," Manag. Innov. a Sustain. Built Environ., no. June, pp. 1-10, (2011)

8. G. Rajasekaran and S. Narasimha Rao, "Lime Stabilization Technique for the Improvement of Marine Clay.," SOILS Found., vol. 37, pp. 97-104, (1997)

9. K. R. D, M. Anusha, P. R. T. Pranav, and G. Venkatesh, "A Laboratory Study on The Stabilization Of Marine Clay Using Saw Dust And Lime,” no. 4, pp. (851862), (2012)

10. H. Kurama and M. Kaya, "Usage of coal combustion bottom ash in concrete mixture," Constr. Build. Mater., vol. 22, no. 9, pp. 1922-1928, (2008)

11. M. Hashan, M. F. Howladar, L. N. Jahan, and P. K. Deb, "Ash Content and Its Relevance with the Coal Grade and Environment in Bangladesh," vol. 4, no. 4, pp. 669-676, (2013)

12. A. Marto, M. a. Hassan, A. M. Makhtar, and B. a. Othman, "Shear Strength Improvement of Soft Clay Mixed with Tanjung Bin Coal Ash," APCBEE Procedia, vol. 5, pp. 116-122, (2013)

13. N. Latifi, A. Marto, A. S. A. Rashid, and J. L. J. Yii, "Strength and Physicochemical Characteristics of Fly Ash-Bottom Ash Mixture," Arab. J. Sci. Eng., vol. 40, no. 9, pp. 2447-2455, (2015)

14. H. W. Xiao and F. H. Lee, "Curing time effect on behavior of cement treated marine clay," Proc. World Acad. Sci. Eng. Technol., vol. 33, no. 7, pp. 2070-3740, (2008)

15. K. Show, J. Tay, and A. Goh, "Reuse of Incinerator Fly Ash in Soft Soil Stabilization," J. Mater. Civ. Eng., vol. 15, no. 4, pp. 335-343, (2003) 